\title{
2B: H. pylori infection in childhood
}

\section{B:01 H. PYLORI INFECTION IN CHILDREN BORN TO SEROPOSITIVE MOTHERS}

M. Ashorn, T. Ruuska, M. Mäki, A. Miettinen. University of Tampere and University Hospital of Tampere, Tampere, Finland

The purpose was to study the long-term course of $H$. pylori infection in children and their parents. Methods: Sera drawn from 14 children born in 1984 with positive IgG-antibody titres to $H$. pylori in their cord blood samples were sequentially tested at the ages of 28 days and at 7,12 and 24 mos. In 1995, at the age of 11 yrs, children were re-tested by serology and ${ }^{13} \mathrm{C}$-urea breath test (UBT). $H$. pylori antibodies were also determined in the mothers to all children and in the fathers of 11 children. Nine originally seronegative children born in the same year served as controls. The parents of control children were also serologically tested ( 8 mothers, 4 fathers). An in-house enzyme immunoassay using $H$. pylori strain ATCC 43504 was applied for antibody determination. For UBT duplicate breath samples were collected before and 30 minutes after administration of ${ }^{13} \mathrm{C}$-urea for the analysis of ${ }^{13} \mathrm{CO}_{2}$. Results: All 14 originally seropositive children became seronegative till the age of 7 mos. The control visit at the age of 11 yrs revealed recurrent abdominal pain in $14 \%$ of these children. Serology was negative as well as the UBT. 12/14 mothers had highly positive IgG antibody titres to $H$. pylori. $5 / 11$ fathers tested were seropositive. Positive history of gi-symptoms was found in $33 \%$ of the mothers. In the control group one child was seropositive and also had a positive UBT result. His parents were both seronegative, his grand-mother having, however, $H$. pylori infection. Conclusions: 1. Maternal seropositivity does not increase the risk of $H$. pylori infection during childhood. 2 . Till the age of 7 mos seropositivity is basicly a reflection of maternal antibody status. 3 . Seroreversion from positive to negative is rare, but it seems to occur.

\section{B:02 THE PREVALENCE OF H. PYLORI ANTIBODIES IN SCHOOL CHILDREN FROM SOUTHERN ESTONIA}

T. Vorobjova ${ }^{1}$, H. Grünberg ${ }^{1}$, M. Oona ${ }^{1}$, H.-I. Maaroos ${ }^{1}$, T. Wadström ${ }^{2}$ R. Uibo ${ }^{1}$. ' University of Tartu, Estonia; ${ }^{2}$ University of Lund, Sweden

Purpose of the study. Our previous study evaluated an extremely high prevalence of $\mathrm{H}$. pylori (HP) antibodies (87\%) in Estonian adult population. Studies on HP prevalence in a nonselected child population are still lacking in Estonia.

Subjects and Method. 379 sera selected by chance from 884 random child population from South Estonian schools, aged 9, 12 and 15 years (prepubertal, pubertal and postpubertal age) were examined for IgG antibodies to HP. Glycine extracted cell-surface proteins of HP strain NCTC $11637(5 \mu \mathrm{g} / \mathrm{ml})$ was used as an antigen in ELISA. The results were expressed as a corrected mean absorbance value in relation to a reference standard (human gammaglobulin, KABI/Pharmacia, Sweden).

Results. IgG antibodies to HP were detected in $212 / 379(56 \%)$ of the studied children; among 9-year-old children in 34/70 (49\%), 12-year-old in $74 / 136(54 \%)$ and among 15 -year-old in $104 / 173(60 \%)$ cases. HP positivity did not differ either between girls, 114/207 (55\%) and boys, 98/172 (54\%) ( $p>0.05$ ). Children living in South Estonian towns have IgG antibodies to HP in $119 / 234$ cases $(51 \%)$, those living in the farms in $29 / 50(59 \%)$ and in settlements in 64/95 $(67 \%)$ cases (the last significantly higher if compared with prevalence in towns; $p=0.006$ ).

Conclusion. School children from Southern Estonia aged 9, 12 and 15 years have high prevalence (49-60\%) of HP infection without significant differences between groups of prepubertal, pubertal and postpubertal age. Children living in settlements have higher prevalence rate of HP infection compared with those living in towns.

\section{B:03 THERAPEUTIC STRATEGIES FOR H. PYLORI IN CHILDREN WITH RECURRENT ABDOMINAL PAIN}

Nimish Vakil, Merja Ashorn. University of Wisconsin, Milwaukee, WI. USA; University of Tampere, Tampere, Finland

The aim of this study was to model the cost-effectiveness of non-invasive testing for Helicobacter pylori in children with recurrent abdominal pain, currently an area of controversy. Methods: A decision analysis tree was developed using established principles. Key assumptions and ranges tested by sensitivity analysis were: Rate of $\mathrm{H}$. pylori infection in children with recurrent abdominal pain $=30 \%$ (range $=5-55 \%$ ), False positive and false negative rate with serology $=5 \%$ (range $=5-25 \%$ ). Eradication success with the antibiotic regimen $95 \%$ (range 65-95\%). Symptomatic cure rate $=28 \%$ (range 5-35\%). The base case cost of serology was $\$ 20$ (office based test) but the model was also tested with costs for a multiwell ELISA (\$80). Base case cost of therapy was $\$ 97$ (range tested \$27-\$200). Results: Serologic testing was the optimal path costing $\$ 788$ compared to $\$ 833$ for empiric therapy and $\$ 829$ for endoscopy per patient treated. Sensitivity analysis demonstrated that serologic testing was less expensive than empiric therapy or endoscopy as long as antibiotic therapy costs were greater than $\$ 33$ and serology costs were $<\$ 61$. Varying the prevalence of H. Pylori infection from 5-55\% did not alter the results of the model. If the symptomatic response rate in children dropped below $9 \%$, initial endoscopy became the optimal path. Varying the eradication rate of $\mathrm{H}$. pylori from $65-95 \%$ or the cost of endoscopy from $\$ 200-1200$ did not alter the results of the model. Conclusions: 1 . Serologic testing for $\mathrm{H}$. pylori is preferable to empiric therapy or initial endoscopy in children with recurrent abdominal pain. 2. Regardless of the combination of antibiotics used, serologic testing is preferable to empirical therapy as long as treatment costs are greater than $\$ 33$, if the false positive rate for serology is less than $20 \%$ and if the cost of serology is less than $\$ 61$.

\section{B:04 TRANSPLACENTAL ANTI-H. PYLORI IgG DOES NOT PROTECT GAMBIAN INFANTS FROM COLONISATION}

J.E.G. Bunn ${ }^{1}$, J.E. Thomas ${ }^{2}$, M. Harding ${ }^{1}$, W.A. Coward ${ }^{1}$,

L.T. Weaver ${ }^{3}$. 'MRC Dunn Nutrition Unit, The Gambia and Cambridge; ${ }^{2}$ University of Newcastle; ${ }^{3}$ University of Glasgow

H. pylori colonisation is common in early infancy in The Gambia. Specific circulating IgG neither eradicates infection nor provides immunity against re-infection in adults, but transplacental acquired maternal IgG may protect infants from early colonisation. We measured maternal, cord and infant specific serum IgG, and compared these to the age of acquisition of $H$. pylori in Gambian infants during the first year of life.

Sixty-five mothers and infants were studied. Blood was collected from all mothers, and cord blood from 34 births. Serial blood samples were obtained from infants at 8 week intervals. Specific IgG antibodies were measured by ELISA, and $H$. pylori infection in infants was detected by monthly ${ }^{13} \mathrm{C}$ urea breath test (UBT). Maternal and cord specific IgG levels correlated $\left(R^{2}=0.747, p<0.0001\right)$. Median specific IgG levels showed an 8 fold fall over the first 6 months of infancy, and then a 2-fold rise by one year.

Sequential IgG immunoblots on sera from four mothers and their infants showed that cord blood and infant sera at 8 weeks produced a pattern of antigen recognition that closely resembled their mothers, whereas sera from the same children at one year of age showed a qualitatively and quantitatively different response. By one year $39 / 65$ infants had established H. pylori colonisation, defined as 3 or more sequential positive UBTs, $10 / 65$ infants had no positive UBTs, and 16/65 infants had some positive UBTs without evidence of established colonisation.

There were no significant associations between the age of first positive UBT, or established $H$. pylori colonisation, and maternal or cord specific IgG level. Gambian mothers transfer specific anti- $H$. pylori IgG to their infants, but this does not appear to confer protection against $H$. pylori colonisation in the first year of life.

\section{B:05 THE ${ }^{13}$ C-UREA BREATH TEST FOR THE DIAGNOSIS OF HELICOBACTER PYLORI INFECTION IN CHILDREN}

The Bologna ${ }^{13} \mathrm{C}$-Urea Breath Test User Group, F. Bazzoli, L. Cecchini ${ }^{~}$, L. Corvaglia, M. Dall'Antonia ${ }^{6}$, M. Dalla Libera ${ }^{2}$, C. De Giacomo ${ }^{4}$, S. Fossi, P. Garisio ${ }^{5}$, L. Gobbio Casali ${ }^{3}$, S. Gullini ${ }^{2}$, R. Lazzari, G. Leggeri ${ }^{3}$, P. Lerro ${ }^{5}$, F. Lizzoli ${ }^{4}$, G. Mandrioli ${ }^{2}$, M. Marani ${ }^{1}$, P. Martelli ${ }^{5}$, A. Miano ${ }^{1}$, C. Mwangemi, G. Oderda ${ }^{5}$, A. Pasetti, P. Pazzi ${ }^{2}$, P. Pozzato, L. Ricciardiello, E. Roda, P. Simoni, S. Sottili, G. Torre ${ }^{6}$, L. Urso ${ }^{6}$, R.M. Zagari. Bologna; ${ }^{1}$ Cesena $;{ }^{2}$ Ferrara $;{ }^{3}$ Mantova $;{ }^{4}$ Pavia; ${ }^{5}$ Torino; ${ }^{6}$ Trieste, Italy

Background. The ${ }^{13} \mathrm{C}$-Urea Breath Test $\left({ }^{13} \mathrm{C}\right.$-UBT $)$ is a simple non-invasive highly accurate test for the detection of Helicobacter (H.) pylori infection in adults. Although the use of ${ }^{13} \mathrm{C}$-labelled urea renders this test absolutely safe and thus undoubtedly suitable for the detection of $\mathrm{H}$. pylori infection in children, as yet a standardized ${ }^{13} \mathrm{C}$-UBT protocol for children has not been formulated. In particular we have no information on the three fundamental 
components of the ${ }^{13} \mathrm{C}$-UBT: the number of and time intervals for breath sample collection, the appropriate test meals to delay gastric emptying and doses of ${ }^{13} \mathrm{C}$-Urea. Aim. The aim of our study was to evaluate the accuracy of the ${ }^{13} \mathrm{C}$-UBT in children using different types of test meal, doses of ${ }^{13} \mathrm{C}$-Urea and breath sampling intervals. Methods. 98 children, recruited in our study (51 males, 47 females; age (yrs) range 2-16, mean \pm SE: 10.1 \pm 0.3 ; body surface area $\left(\mathrm{m}^{2}\right)$ range $0.5-1.7$, mean \pm SE: $\left.1.2 \pm 0.03\right)$ underwent routine upper GI endoscopy. 3 antral and 2 corpus-fundus biopsy specimens were taken for histological evaluation for the presence of $\mathbf{H}$ pylori infection (Haematoxylin/Eosin; GIEMSA) and the quick Urease-test was performed. The ${ }^{13} \mathrm{C}$-UBT was performed in each child after undergoing endoscopy, and was then repeated within three days modifying the test meal or the dose of the ${ }^{13} \mathrm{C}$-Urea. 62 children were given a fatty test meal, Pulmocare (Abbott) $100 \mathrm{ml}$, and two different doses of ${ }^{13} \mathrm{C}$-Urea, 100 and $50 \mathrm{mg}$ respectively. 36 children were given the same dose of ${ }^{13} \mathrm{C}$-Urea, 50 $\mathrm{mg}$, but two different types of test meal, Pumocare $100 \mathrm{ml}$ and $10 \mathrm{~g}$ at $10 \%$ of Polycose (polymer of glucose) respectively. Breath samples were collected every 10 minutes for 60 minutes and analyzed by an Automated Breath ${ }^{13} \mathrm{C}$ Analyzer (ABCA Europa Scientific). The "gold standard" for the detection of $\mathrm{H}$. pylori infection was defined as a concordant result on histology and quick urease-test. The cut-off value was calculated taking the mean of $\mathrm{H}$. pylori -ve subjects \pm 3 SD and using a ROC curve. Results. According to the "gold standard" 48 children were considered H. pylori +ve and $44 \mathrm{H}$. pylori -ve.

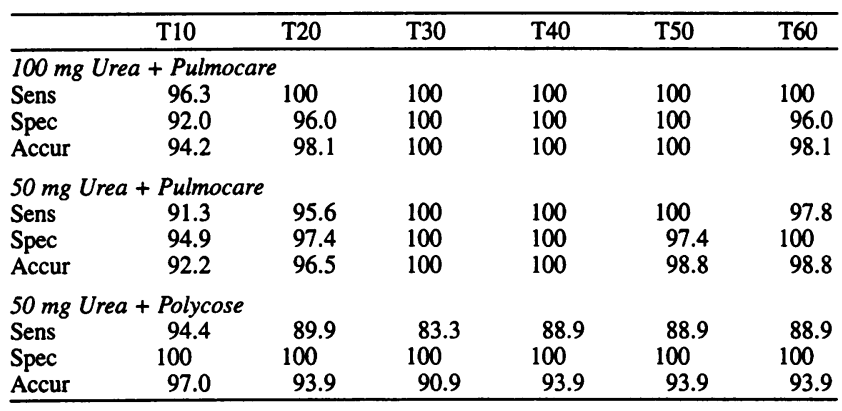

Conclusions. The ${ }^{13} \mathrm{C}$-UBT is a simple, non-invasive test that can be used as the "gold standard" for the detection of H. pylori infection. Administering $50 \mathrm{mg}$ of ${ }^{13} \mathrm{C}$-Urea, a fatty test meal and a single breath sample at T30 makes it ideal even in children.

\section{B:06 PREVALENCE OF H. PYLORI INFECTION IN SPANISH SCHOLARS CHILDREN RELATED TO GASTRIC SYMPTOMATOLOGY}

M.J. Martínez, J. Asensio, J.C. Sanz, M. Sánchez-Bayle, M.T. Conde, M. López-Brea. U. Gastroenterología, S. Pediatría, S. Análisis clínicos, Hospital Niño Jesús, Madrid, Spain; S. Microbiologia Hospital de la Princesa, Madrid, Spain

Purpose: to determinate the relation between the presence of specific IgG antibodies against $H$. pylori $(\mathrm{Hp})$ with the clinical manifestations of upper gastrointestinal (GI) tract disease (abdominal or epigastric pain and/or vomits) in scholars children from Madrid.

Methods: 285 sera samples of 285 scholars ( 157 males and 128 females; median age $9.9 \pm 3.6$ years) were tested for specific IgG against $\mathrm{Hp}$ by using a EIA test (HELICO G. Porton Cambridge).

A questionnaire about the presence of abdominal or epigastric pain and vomits was answered by each children.

Results: 73 children (25.6\%) were found to be positive for specific IgG against $\mathrm{Hp}, 18$ of them (24.6\%) referred upper GI symptoms. Of the 212 children without IgG for Hp (74.4\%), only 23 (10.8\%) manifested upper GI symptomatology.

Conclusions: (1) The seroprevalence for Hp was high in this Spanish children population. (2) It was a significant association $(p<0.01)$ between seropositivity against $\mathrm{Hp}$ and upper GI clinical manifestations. (3) However, a high number of scholars with antibodies against Hp were asymptomatic.

\section{B:07 FAILURE OF OMEPRAZOLE PLUS AMOXICILLIN THERAPY IN H. PYLORI INFECTED SPANISH CHILDREN}

M.J. Martínez, P. Urruzuno, M.L. Cilleruelo, M. Sebastián, D. Madruga, J.C. Sanz, M. López-Brea. H. Niño Jesús, $H 12$ Octubre, H. S. Ochoa, $H$. Móstoles, H. Getafe y, H. Princesa, Madrid, Spain

Purpose: Omeprazole plus Amoxicillin therapy has been described to reach high $H$. pylori $(\mathrm{Hp})$ eradication rates. The objective of this study was to know the efficacy of this therapy for Hp antral gastritis in Spanish children.
Methods: 32 children (22 females and 10 males) aged between 12-17 years (median age 12.9 years) with $\mathrm{Hp}$ antral gastritis diagnosed by ${ }^{13} \mathrm{C}$ Urea Breath Test $\left({ }^{13} \mathrm{C}\right.$-UBT) and endoscopy (histology and microbiological culture) were studied.

All patients were treated with Omeprazole $(20 \mathrm{mg} /$ day $)$ and Amoxicillin $(50 \mathrm{mg} / \mathrm{Kg} /$ day, t.i.d.) during two weeks. One month after finishing therapy a second ${ }^{13} \mathrm{C}$-UBT was performed to monitoring treatment. Eradication was defined as ${ }^{13} \mathrm{C}$-UBT $<5$ per 1,000 . The alternative treatment regimen for most of the non eradicated patients was Omeprazole $(20 \mathrm{mg} /$ day $)$ plus Clarithromycine $(15 \mathrm{mg} / \mathrm{Kg} /$ day b.i.d.) during two weeks.

Results: Eradication was achieved in only 5 patients who received Omeprazole plus Amoxicillin (15.6\%). In 22 of the non-eradicated patients, a new trial with Omeprazole plus Clarithromycine was instaured, obtaining the eradication in 13 of them (59\%).

Conclusions: (1) Omeprazole plus Amoxicillin had a low efficacy in the eradication of $\mathrm{Hp}$ infection in Spanish children. (2) The retreatment with Omeprazole plus Clarithromycine had a moderate efficacy among Omeprazole-Amoxicilline non-responders patients.

\section{B:08 TITER OF IgG AND IgA ANTIBODIES AND Cag-A GEN IN $H$. PYLORI INFECTED CHILDREN}

M. López-Brea, T. Alarcón, M.J. Martínez, I. Sánchez, J.C. Sanz. Hospital de la Princesa, Hospital Niño Jesús, Madrid, Spain

Purpose: To relate infection by cagA strains and $\operatorname{IgG}$ and $\operatorname{IgA}$ specific systemic response in $H$. pylori $(\mathrm{Hp})$ infected children.

Methods: 33 children submitted to gastroscopy and with Hp culture positive were studied. cagA gen was detected, by previously described PCR protocol, in the isolates from 11 patients (mean age $12.4 \pm 4.5$ years) and was non observed in the strains from 22 children (mean age $10 \pm 3.4$ years). Serum from each patient was taken at the time of the endoscopy. The serological detection of IgG and IgA was performed by EIAs (EIA-G and EIA-A Pyloriset; Orion Diagnostica).

Results: The distribution of the IgG and IgA titers among cagA positive and negative patients and the statistical association for every serological level was as follows:

\begin{tabular}{lllllll}
\hline & $\operatorname{IgG} \geq 2500$ & $\geq 2000$ & $\geq 1500$ & $\geq 1000$ & $\geq 500$ & $\geq 200$ \\
\hline cagA+ (11) & 7 & 8 & 8 & 10 & 11 & 11 \\
cagA- (22) & 2 & 4 & 6 & 11 & 17 & 19 \\
& $\mathrm{p}<0.005$ & $\mathrm{p}<0.005$ & $\mathrm{p}<0.05$ & $\mathrm{p}<0.05$ & $\mathrm{p}>0.1$ & $\mathrm{p}>0.1$ \\
& $\mathrm{IgA} \geq 2500$ & $\geq 2000$ & $\geq 1500$ & $\geq 1000$ & $\geq 500$ & $\geq 200$ \\
\hline cagA+(11) & 1 & 1 & 1 & 4 & 5 & 9 \\
cagA- (22) & 0 & 0 & 0 & 2 & 5 & 12 \\
& $\mathrm{p}<0.1$ & $\mathrm{p}>0.1$ & $\mathrm{p}>0.1$ & $\mathrm{p}>0.1$ & $\mathrm{p}>0.1$ & $\mathrm{p}>0.1$ \\
\hline
\end{tabular}

A significant lineal trend between infection by cagA+ and increasing titer of IgG $(<1000, \geq 1000<2500 \& \geq 2500$; p < 0.005) and $\operatorname{IgA}(<$ 200 , $\geq 200<1000 \& \geq 1000 ;<0.05$ ) was noted.

Conclusions: The IgG and IgA serological response seems to be higher among children infected by cagA+ strains. Elevated systemic IgG levels in children could indicate infections by more virulent strains.

\section{B:09 ASSOCIATION BETWEEN ACTIVE GASTRITIS AND IgG LEVEL AND REACTIVITY AGAINST SEVERAL H. PYLORI ANTIGENS IN INFECTED CHILDREN}

J.C. Sanz, M.J. Martínez, T. Alarcón, I. Sánchez, M. López-Brea. Hospital de la Princesa, Hospital Niño Jesús. Madrid, Spain

Purpose: To study the relation among gastric histological lesion and IgG serological level in $H$. pylori (Hp) children.

Methods: Sera samples from 2 groups of $\mathrm{Hp}$ infected children (culture+ or histology+) were studied: 10 patients (mean age $9.9 \pm 3.1$ years) with active gastritis (AG) and 38 (mean age $10.2 \pm 3.4$ years) with non-active gastritis (NAG).

The serological IgG titer against $\mathrm{Hp}$ and the reactivity to several bacterial antigens $(19.5,26.5,30.5,35.5,89$ and $116 \mathrm{kD}$ proteins) were determinate by using a quantitative EIA (EIA-G Pyloriset; Orion Diagnostica) and a western blot (Helicoblot 2.0, Genelabs) respectively.

Results: A significant lineal trend between AG and number of reactive blotting bands ( $\leq 3,4,5$ and 6 bands; $p<0.01$ ) and between $A G$ and IgG Pyloriset titer $(\leq 500, \geq 500 \&<1500, \geq 1500 \&<3500, \geq 3500$;

\begin{tabular}{lrrrlll}
\hline & AG & NAG & SEN & SPE & DA & \\
\hline 89 \& 116 kD+ & 7 & 12 & 70 & 68.4 & 68.7 & $\mathrm{p}<0.05$ \\
$\geq 3$ bandst & 10 & 26 & 100 & 31.5 & 45.8 & $\mathrm{p}<0.05$ \\
$\geq 4$ bands+ & 9 & 19 & 90 & 50 & 58.3 & $\mathrm{p}<0.05$ \\
$\geq$ 5 bands+ & 7 & 9 & 70 & 76.3 & 75 & $\mathrm{p}<0.01$ \\
$\geq 6$ bands+ & 5 & 4 & 50 & 89.4 & 81.2 & $\mathrm{p}<0.05$ \\
IgG $\geq 3500$ & 4 & 4 & 40 & 89.4 & 79.1 & $\mathrm{p}<0.05$ \\
\hline
\end{tabular}


$\mathrm{p}<0.05$ ) was noted. The sensitivity (SE), specificity (SP) and diagnostic accuracy (DA) for AG in infected children, according to the reactivity to some proteins, number of blotting bands and titer was as shown in the table.

Conclusions: High serological IgG titers and presence of specific antibodies against several $\mathrm{Hp}$ antigens seems to be more frequent among AG than in NAG infected children.

\section{B:10 IgG ANTIBODIES AGAINST SPECIFIC PROTEIC ANTIGENS IN cag-A+ AND cag-A - H. PYLORI INFECTED CHILDREN}

J.C. Sanz, T. Alarcón, J. Martínez, D. Domingo, M. López-Brea. Hospital de la Princesa, Hospital Niño Jesús, Madrid, Spain

Purpose: To study the IgG response to $H$. pylori $(\mathrm{Hp})$ specific antigens in children infected by cagA+ and cagA - strains.

Methods: 21 symptomatic children submitted to gastroscopy and with Hp culture positive were studied. The presence of cagA gen was detected (by a previously described PCR protocol) in the isolates from 6 patients (mean age $10.8 \pm 3.5$ years) and was not observed in the strains from 15 children (mean age $10.1 \pm 2.4$ years). Serum from each patient was taken at the moment of the endoscopy. Serological IgG against some Hp proteins $(19.5,26.5,30.5,35.5,89$ and $116 \mathrm{kD})$ was detected by western blot (Helicoblot 2.0, Genelabs).

Results: The distribution of western blot reactive bands among cagAt and cagA- infected children was as follows:

\begin{tabular}{llcl}
\hline & cagA+(n=6) & cagA- $(\mathrm{n}=15)$ & $\mathrm{N}=21$ \\
\hline $19.5 \mathrm{kD}$ & $4(66.6 \%)$ & $9(60 \%)$ & $13(61.9 \%)$ \\
$26.5 \mathrm{kD}$ & $6(100 \%)$ & $13(86.6 \%)$ & $19(90.4 \%)$ \\
$30 \mathrm{kD}$ & $6(100 \%)$ & $14(93.3 \%)$ & $20(95.2 \%)$ \\
$35 \mathrm{kD}$ & $1(16.6 \%)$ & $9(60 \%)$ & $10(47.6 \%)$ \\
$89 \mathrm{kD}$ & $4(66 \%)$ & $4(26.6 \%)$ & $8(38 . \%)$ \\
$116 \mathrm{kD}$ & $4(66 \%)$ & $2(13.3)$ & $6(28.5 \%)$ \\
\hline
\end{tabular}

A significant association between infection by cagA+ and IgG against the $116 \mathrm{kD}$ protein was noted ( $\mathrm{p}<0.05$; Odds Ratio $13,95 \%$ Confidence Interval 0.92-210.26).

Conclusions: Although no association between reactivity to the $89 \mathrm{kD}$ antigen (vacA) and cagA was found, the positivity against this band was related to positivity to the $116 \mathrm{kD}$ protein (the 4 cagAt and $116 \mathrm{kD}+$ children and the $2 \mathrm{cagA}-$ but $116 \mathrm{kD}+$ showed reactivity to the $89 \mathrm{kD}$ protein).

\section{B:11 ONE WEEK VS TWO WEEKS TRIPLE THERAPY FOR HELICOBACTER PYLORI ERADICATION IN CHILDREN}

P. Urruzuno, M.L. Cilleruelo, M.J. Martinez, D. Madruga, M. Sebastián, E. Román, E. Medina, J. Manzanares, M. López-Brea. H. 12 de Octubre, $H$. Severo Ochoa, $H$. Niño Jesús, $H$. Getafe, H. Móstoles and H. de la Princesa, Madrid, Spain

Introduction. The aim of this study was to compare the efficacy in H. pylori (Hp) eradication of two weeks and one week triple therapy in order to simplify the therapeutic standard in children.

Patients and methods. We studied 82 children ( 74 chronic gastritis and 8 peptic ulcers), mean age 10 years (range 3-17 years) with a documented $\mathrm{Hp}$ infection by histology, urease test, culture and $13 \mathrm{C}$ urea breath test. Eradication of $\mathrm{Hp}$ was based on a negative breath test one and six months after treatment. Patients were randomly treated with two weeks $(n=43$, group A) and one week ( $n=39$, group B) of the combination schedule: colloidal bismuth subcitrate $(8 \mathrm{mgr} / \mathrm{k} / \mathrm{d})$, amoxicillin $(50 \mathrm{mgr} / \mathrm{k} / \mathrm{d})$ and metronidazole $(20 \mathrm{mgr} / \mathrm{k} / \mathrm{d})$.

Results. One month after treatment, eradication was achieved in $81 \%$ and $79 \%$ in group A and B respectively. Rate of reinfection was $3 \%$ at 6 months of follow up. Of the patients with eradicated Hp symptoms improved in $84 \%$. However, symptoms also improved in $13 \%$ of the non eradicated children.

Conclusion. One week triple therapy is a logical alternative for $\mathrm{Hp}$ eradication in children.

\section{B:12 EVALUATION OF HELICOBLOT 2.0 TEST IN THE FOLLOW-UP OF H. PYLORI INFECTED CHILDREN AFTER THERAPY}

J. Yahav, A. Fradkin, B. Welsselberg, A. Diver-Haber, A. Jonas. Pediatric Gastroenterology Unit, Sheba Medical Center, Tel-Hashomer, Israel

Helicoblot 2.0 is reliable in the diagnosis of $\mathrm{H}$. pylori infection providing specific information of Cag A strains.

We studied the performance of the test in evaluating eradication of treated patients. 63 children $(12.6 \pm 3.3 \mathrm{y})$ were diagnosed as $\mathrm{H}$. pylori positive by biopsy related tests (CLO, histology, culture). The immunoblot
(Helicoblot 2.0 Genalab Singapore) was positive in all (criteria provided by the manufacturer). 34/63 were Cag A positive and 29/63 were Cag A negative. Eradication of Infection (by antral biopsy or ${ }^{13} \mathrm{C}$ UBT) was determined after identical periods of follow up $(28.8 \pm 18 \mathrm{mo}$. Vs $33.2 \pm$ $18 \mathrm{mo}$.) and the immunoblot repeated; 8/34 Cag A positive and 14/29 Cag A negative patients had eradicated infection after comparable periods of time. Correlation with immunoblot are shown in table:

\begin{tabular}{|c|c|c|c|c|c|c|c|}
\hline \multirow[b]{2}{*}{ Immunology } & \multicolumn{3}{|c|}{ Cag A positive } & \multicolumn{3}{|c|}{ Cag A negative } & \multirow[t]{2}{*}{ All } \\
\hline & Positive & Negative & Total & Positive & Negative & Total & \\
\hline \multicolumn{8}{|l|}{ Bacteriology } \\
\hline Positive & 26 & 0 & 26 & 14 & 1 & 15 & 41 \\
\hline Negative & 6 & 2 & 8 & 7 & 7 & 14 & 22 \\
\hline Total & 32 & 2 & 34 & 21 & 8 & 29 & 63 \\
\hline
\end{tabular}

40/41 (97.5\%) patients with persistent infection had positive immunoblot. The $116 \mathrm{Kd}$ band remained unchanged in all. $13 / 22(59 \%)$ patients with eradicated infection had positive immunoblots: $6 / 8 \mathrm{Cag} \mathrm{A}$ positive (75\%) and 7/14 (50\%) Cag A negative, discrepancies were mainly based on: a) persistent $116 \mathrm{Kd}$ band in Cag A positive group. b) persistence of urease related bands (mainly $26.5 \mathrm{Kd}$ ) in Cag A negative group, which was time related $(30.3 \pm 22 \mathrm{mo}$. In seronegative Vs $13.6 \pm 9.0 \mathrm{mo}$. in persistent seropositive, $\mathrm{p}=0.04$ ).

Conclusion: The $116 \mathrm{kd}$ protein is strongly immunogenic and persists for prolonged periods of time. Negativization of immunoblot in Cag A negative patients may be time dependent.

\section{B:13 HELICOBACTER PYLORI (HP) IN NORMAL AND IPOSOMIC CHILDREN}

M. Menegatti, S. Salardi, D. Vaira, F.A. Stella, N. Figura, A. Alì, J. Holton, F. Landi, C. Ricci, F. Mucci, M. Miglioli, E. Cacciari. Dept. of Paediatric \& Ist Medical Clinic, University of Bologna, Italy; Dept. of Int Med, University of Siena, Italy; Microbiology Dept. University College London Hospital, London, UK

Recent reports (BMJ 1994; 309: 1119-23) suggest a possible involvement of HP on impaired growth in infected children. Aim: To evaluate HP seroprevalence in auxhologically normal (AN) and iposomic (I) children with similar sociodemographic background attending Paediatric Clinic for non gastrointestinal diseases. Methods: HP was assessed firstly by IgG ELISA previously validated with sensitivity and specificity of $94 \%$ in adults (cut-off 0.30 of Absorbance Index) (AI). For the children population the IgG cut-off was arbitrarily chosen as the half value of the adults. To validate the $0.15 \mathrm{AI}$ cut-off all children with $\mathrm{AI}>0.15$ and a random sample $(\mathrm{N}=29)$ of children with $\mathrm{AI} \leq 0.15$ were also assessed by Western Blotting (WB) and ${ }^{13} \mathrm{C}$-Urea Breath MAT test (UBT) (Cortex, Italia). HP was considered positive if at least 2 out of 3 tests were positive. Children were defined iposomic if below the third percentile and normal if over the forthieth for the corresponding age. Results: 326 children (M/F: 162/164; range 2-16, mean 9 yrs) of whom 168 AN (M/F: 71/97, range 2-15 yrs, mean $7 \mathrm{yrs}$ ), and $158 \mathrm{I}$ (M/F: 91/67, range 2-16 yrs, mean $11 \mathrm{yrs)}$ were enrolled. $31 / 326$ were $>0.15 \mathrm{AI}$; in $25 / 31$ positivity was confirmed by WB and/or UBT $(N=15)$, on $6 / 31$ WB and UBT $(N=6)$ were negative. All the 29 controls with $\mathrm{AI} \leq 0.15$ were WB and UBT $(\mathrm{N}=7)$ negative. Overall $25 / 324(7.7 \%)$ were found to be HP +ve at WB/IgG and UBT $(\mathrm{n}=14)$ of whom $15 / 158 \mathrm{I}(10.1 \%)$ and $9 / 168 \mathrm{AN}(5.3 \%)$. Conclusion: Our preliminary results show a higher seroprevalence of HP in iposomic children, the possible clinical significance is under evaluation.

\section{B:14 ANTRAL NODULARITY IN H. PYLORI INFECTED CHILDREN IS NOT RELATED TO THE HISTOLOGICAL OR SEROLOGICAL RESPONSE}

H.M. Mitchell ${ }^{1}$, E. Beacham ${ }^{1}$, S.L. Hazell ${ }^{1}$, T. Bohane ${ }^{2} .{ }^{1}$ The

University of New South Wales, Australia; ${ }^{2}$ Sydney Children's Hospital, Sydney, Australia

Aim: To examine the histological response to $H$. pylori in symptomatic children with and without antral nodularity and to investigate the relationship between histopathology and the serum immune response to specific $H$. pylori antigens.

Methods: $21 \mathrm{H}$. pylori +ve children (6-18 years) with antral nodularity (Group 1) and $17 \mathrm{H}$. pylori +ve children (9 mths-18 years) without antral and nodularity (Group 2) were studied. Histological sections from the antrum and body were graded using the Sydney system. The immune response to specific $H$. pylori antigens was determined using Western blot analysis.

Results are shown in Table 1. No significant difference was found between children with and without nodules with respect to immune response or histology. In a proportion of children with nodularity, the size of antral LF was increased compared to those without nodules. In Group 1 \& 2 
Table 1. Histological response in Hp positive children

\begin{tabular}{llrlrrrrrr}
\hline Group & Grade & $\begin{array}{l}\text { Hp } \\
\text { Ant }\end{array}$ & $\begin{array}{l}\text { Hp } \\
\text { Body }\end{array}$ & $\begin{array}{l}\text { CI } \\
\text { Ant }\end{array}$ & $\begin{array}{l}\text { CI } \\
\text { Body }\end{array}$ & $\begin{array}{l}\text { PMN } \\
\text { Ant }\end{array}$ & $\begin{array}{l}\text { PMN } \\
\text { Body }\end{array}$ & $\begin{array}{l}\text { LF } \\
\text { Ant }\end{array}$ & $\begin{array}{l}\text { LF } \\
\text { Body }\end{array}$ \\
\hline 1 & 0 & 0 & 3 & 0 & 0 & 11 & 13 & 14 & 17 \\
$(\mathrm{n}=21)$ & 1 & 7 & 9 & 2 & 11 & 7 & 7 & 7 & 4 \\
& 2 & 11 & 7 & 17 & 9 & 3 & 1 & 0 & 0 \\
& 3 & 3 & 2 & 2 & 1 & 0 & 0 & 0 & 0 \\
2 & 0 & 0 & 3 & 0 & 0 & 5 & 9 & 12 & 15 \\
$(\mathrm{n}=17)$ & 1 & 8 & 8 & 2 & 9 & 8 & 4 & 4 & 2 \\
& 2 & 6 & 4 & 13 & 8 & 3 & 3 & 0 & 0 \\
& 3 & 3 & 2 & 2 & 0 & 1 & 1 & 1 & 0 \\
\hline
\end{tabular}

Hp: H. pylori, CI: Chronic inflammation, PMN: Polymorphonuclear cells, LF: Lymphoid follicles.

a significant association between response to the $128 \mathrm{kDa}$ and $116 \mathrm{kDa}$ antigen and increased levels of PMN in the antrum and body $(p=0.0009$ $\& p=0.009)$ and $(p=0.002 \& p=0.008)$ was noted.

Conclusion: In children, antral nodularity is not associated with histopathology or the serum immune response. As in adults, the antibody response to the $128 \mathrm{kDA}$ antigen $(\mathrm{CagA})$ in children is associated with increased PMN infiltration.

\section{B:15 SALIVARY DIAGNOSIS OF HELICOBACTER PYLORI INFECTION IN CHILDREN: A MULTICENTER STUDY}

F. Luzza, G. Oderda ${ }^{1}$, S. Guandalini ${ }^{2}$, M. Maletta, L. Mesuraca ${ }^{2}$, M. Imeneo, A. La Vecchia ${ }^{3}$,E. Chiorboli ${ }^{1}$, P. Lerro ${ }^{1}$, L. Tucci ${ }^{3}$, C. Docimo ${ }^{3}$, F. Pallone. ${ }^{2}$ Dipartimento di Medicina Sperimentale, Cattedra di Pediatria, Univ di R. Calabria, Catanzaro, Italy; ${ }^{1}$ Clinica Pediatrica, Univ di Torino, Italy; ${ }^{3}$ Servizio di Anatomia Patologia, Ospedale Pugliese, Catanzaro, Italy

Epidemiological studies suggest that in most populations $H$. pylori infection is commonly acquired in childhood. Serology is a sensitive and specific indicator of $H$. pylori infection also in pediatric population, provided that children's sera are used to standardize the assay. We have recently shown that salivary IgG to $H$. pylori paralleled specific circulating IgG and accurately detected $H$. pylori infection in adults (Am J Gastro 1995). In this study we validated our salivary test to diagnose $H$. pylori infection in children. 112 consecutive patients ( $55 \mathrm{M}$; median age: 11 yrs, range 2-18) attending for upper GI endoscopy were available for the study. Two antral and corpus biopsy specimens were taken for histology (Giemsa staining) and one antral biopsy for urease quick test. Assessments were made blinded to the final diagnosis. Where both evaluations were concordant this was taken as the gold standard $H$. pylori status for that patient. $1-2 \mathrm{ml}$ of unstimulated saliva were collected from each patient before endoscopy and stored at $-20^{\circ} \mathrm{C}$ until tested. Saliva samples (working dilution 1:2) were assayed for $H$. pylori IgG by an in-house ELISA using a sonicate of a whole $H$. pylori strain as antigen. All samples were run in duplicate in the same assay. A cut-off of 2 SD above the mean of a standard reference pool of histologically $H$. pylori negative children's saliva was chosen. Results were expressed as mean optical density (OD) \pm SD. 95\% CI were given. $H$. pylori was identified in $57(51 \%)$ patients. Salivary $H$. pylori IgG were significantly higher in $H$. pylori positive than negative patients $(0.495 \pm 0.292$ vs $0.150 \pm 0.131, \mathrm{p}<0.001)$. Based on a cut-off of 0.200 $\mathrm{OD}$, we found that $4 \mathrm{H}$. pylori positive patients were saliva negative and $10 \mathrm{H}$. pylori negative were saliva positive. The sensitivity and specificity of salivary $H$. pylori $\operatorname{IgG}$ were $93 \%(83-98 \%)$ and $82 \%$ (70-91\%) with positive and negative predictive values of $84 \%$ (73-92\%). Salivary $H$. pylori IgG is an accurate indicator of gastric $H$. pylori colonization in pediatric population. It may offer practical advantages in children in both clinical and investigational settings.

\section{B:16 13C-UREA BREATH TEST FOR THE DIAGNOSIS OF HELICOBACTER PYLORI IN CHILDREN}

M. Rowland ${ }^{1}$, I. Lambert ${ }^{1}$, S. Gormally ${ }^{1}$, J.E. Thomas ${ }^{2}$, L.E. Daly ${ }^{3}$, M. Durnin ${ }^{1}$, B. Drumm ${ }^{1,3} .1$ Children's Research Centre Our Lady's Hospital for Sick Children, Dublin, Ireland; ${ }^{2}$ University of Newcastle, UK; ${ }^{3}$ University College Dublin, Ireland

Background H. pylori infection is mainly acquired in childhood and studies of the epidemiology of this infection depend on the availability of a non-invasive diagnostic test for use in children.

Aim to determine if the ${ }^{13} \mathrm{C}$-urea breath test (UBT) can be used in children by evaluating (a) its sensitivity and specificity against a specific gold standard of either culture or both a rapid urease test and histology (b) if a test meal or a prolonged fast are required (c) its usefulness following treatment for $H$. pylori. Methods. Eighty eight children (mean age 10.6 SD. 4.19, M:F 2.3:1) undergoing upper endoscopy were studied. Tests were performed fasting, non-fasting and after treatment. Children were given 50 $\mathrm{mg}{ }^{13} \mathrm{C}$-urea $(<50 \mathrm{~kg})$ or $75 \mathrm{mg}{ }^{13} \mathrm{C}$-urea $(>50 \mathrm{~kg})$ with $50 \mathrm{mg}$ of a glucose polymer solution in $7.5 \mathrm{ml}$ of water. Breath samples were collected at baseline $15,30,45$, and 60 minutes.

Results The UBT was $100 \%$ sensitive and $97.6 \%$ specific at $30 \mathrm{~min}$ using a cut-off value of $3.5 \delta{ }^{13} \mathrm{CO}_{2}$ per mil. Non-fasting tests in 23 children performed 2 hours after their usual meal were $100 \%$ sensitive and $91.6 \%$ specific at $3.5 \delta^{13} \mathrm{CO}_{2}$ per mil ( 1 false positive). However $\delta$ values were reduced in non fasting children. In 13 children fed with ice-cream and a cola drink directly before the UBT the sensitivity of the test was reduced to $50 \%$. Thirty minutes was the optimal sampling time. There was a significant decrease in specificity $(58 \%)$ when samples were obtained at 15 minutes possibly due to oral urease producing organisms. The test was $100 \%$ sensitive and specific at a cut-off of $3.5 \delta^{13} \mathrm{CO}_{2}$ per mil in 20 infected children after treatment for $H$. pylori.

Conclusion The UBT is an extremely useful test for the diagnosis of $H$. pylori infection in children. A 2 hour fast is sufficient, and $\mathbf{3 0}$ minutes is the optimal sampling time. A test meal is not required and may interfere with the sensitivity of the test. The UBT is an ideal test for studies on the epidemiology of $H$. pylori in children.

\section{B:17 H. PYLORI SALIVA-POSITIVITY IN JAPANESE CHILDREN AGED 1.5, 3, 6 AND 14 YEARS}

S. Kikuchi ${ }^{1}$, M. Kurosawa ${ }^{1}$, H. Ishizu ${ }^{2}$, T. Ishibashi ${ }^{3}$, Y. Yamashiro ${ }^{1}$, M. Oguchi ${ }^{1}$, K. Shinohara ${ }^{1}$, Y. Inaba ${ }^{1},{ }^{1}$ Juntendo Univ. Sch. Med. Tokyo, Japan; ${ }^{2}$ Takatsu Health Center, Kawasaki, Japan; ${ }^{3}$ Asama Hosp., Saku, Japan

Purpose: To assess prevalence of $H$. pylori infection in Japanese children. Subjects and Methods: Saliva samples were collected from 18 and 36month-old children who underwent health checks at a health center in an urban area of Japan and from 6 and 14-year-old school children in a rural area of Japan. Anti-H. pylori IgG antibody in saliva was measured by SRL Co. Ltd., Japan using 'Helisal' kits produced by Cortecs Ltd., UK.

Results: Children aged 3 and 6 years showed high saliva-IgG positivity rates compared with 18-month and 14-year old subjects.

Table Saliva-IgG positive rates in Japanese children

\begin{tabular}{llrl}
\hline Age & Male & Female & Total \\
\hline 18 months & $2 / 48(4.2 \%)$ & $2 / 47(4.3 \%)$ & $4 / 95(4.2 \%)$ \\
36 months & $16 / 51(31.4 \%)$ & $19 / 61(31.2 \%)$ & $35 / 112(31.3 \%)$ \\
6 years & $27 / 153(17.6 \%)$ & $39 / 152(25.7 \%)$ & $66 / 305(21.6 \%)$ \\
14 years & $12 / 152(7.9 \%)$ & $5 / 130(3.8 \%)$ & $17 / 282(6.0 \%)$ \\
\hline
\end{tabular}

Children posisive/tested (positive \%)

Conclusion: It is hypothesized that children aged 3-6 years are exposed to $H$. pylori but persistent infection occurs to only some of them. Saliva is being collected from the children aged previously 6 and 14 years, 1 year after the first collection, and follow-up results will be reported.

\section{B:18 ONE WEEK THERAPY FOR HELICOBACTER PYLORI INFECTION IN CHILDREN}

D. Walsh, N. Goggin, M. Durnin, S. Moriarty, B. Drumm. Dept. of Paediatrics, University College Dublin, Ireland; Children's Research Centre, Our Lady's Hospital for Sick Children, Dublin, Ireland

Helicobacter pylori is associated with primary gastritis and duodenal ulceration in adults and children. Recent studies suggest an association between $H$. pylori infection acquired in childhood and gastric cancer. Current regimes aimed at eradication of infection in children using bismuth and antibiotics for two to six weeks are cumbersome.

Aim: To evaluate the efficacy of a one-week course of treatment in eradicating $H$. pylori.

Methods: All children undergoing endoscopy were assessed for the presence of $H$. pylori by culture, histology, rapid urease test and ${ }^{13} \mathrm{C}$ urea breath test $\left({ }^{13} \mathrm{C} \mathrm{UBT}\right)$. Twenty-two children infected with $H$. pylori were entered into the study. They received a one-week course of colloidal bismuth subcitrate: $480 \mathrm{mg} / 1.73 \mathrm{~m}^{2} /$ day (maximum $120 \mathrm{mg}$ qid), combined with metronidazole: $20 \mathrm{mg} / \mathrm{kg} /$ day (maximum $200 \mathrm{mg}$ tds), and clarithromycin: $7.5 \mathrm{mg} / \mathrm{kg} /$ day (maximum $250 \mathrm{mg}$ bd). To optimise compliance, drugs were dispensed in a "Redidose" box containing a compartment for each day, and sub-compartments marked "breakfast", "lunch", "dinner" and "bedtime". Compliance and side-effects were assessed immediately after treatment. ${ }^{13} \mathrm{C}$ UBT was used to assess eradication. This was performed at least one month following the completion of treatment.

Results: $H$. pylori was eradicated in twenty-one of the 22 children treated $(95.45 \%)$. Twenty of these 22 children took all doses. Two children suffered significant side-effects of diarthoea and vomiting.

Conclusion: This study demonstrates that $H$. pylori infection in children can be eradicated by a one-week course of treatment when compliance is carefully monitored. 


\section{B:19 SERODIAGNOSIS OF HELICOBACTER PYLORI IN A PAEDIATRIC POPULATION USING QUICKVUE ONE-STEP - A RAPID IMMUNOASSAY}

D. Walsh ${ }^{1,3}$, L. Howard ${ }^{3}$, S. Rose ${ }^{2}$, M. Clyne ${ }^{3}$, A. Pronovost ${ }^{2}$, B. Drumm 1,3.' Dept of Paediatrics, University College Dublin, Ireland; ${ }^{2}$ Quidel Corp., San Diego, CA, USA $;{ }^{3}$ Children's Research Centre, Our Lady's Hospital for Sick Children, Dublin, Ireland

Aim: To evaluate the sensitivity and specificity of QuickVue One-Step, a rapid, visually-read immunoassay, to detect antibodies to $H$. pylori, in a paediatric population. Methods: Serum from 164 children undergoing upper endoscopy was collected and stored at $-70^{\circ} \mathrm{C}$. Children were excluded if they were on systemic antibiotics less than one month before endoscopy, or if there was documented immunodeficiency. Mean age was 11 years (range 4 months-16 years). Male:female ratio was 1.5:1. Results of gastric biopsies were used as Gold Standard in diagnosis of $H$. pylori infection. Children were considered infected if they were positive on culture or both rapid unease test and histology. They were considered negative if no test was positive. Subsequently, the serum was tested by QuickVue One-Step - a lateral-flow immunoassay intended for the rapid qualitative detection of IgG antibodies specific to $H$. pylori. Three drops (app $100 \mu \mathrm{l}$ ) of serum was added to the test cassette, which was read at 10 minutes. If antibody is present, a red line appears. We compared the test results and those of a commercial enzyme immunoassay (Quidel) with the diagnosis of $H$. pylori using gastric biopsy. Results Results for QuickVue were as outlined in the table below:

\begin{tabular}{llcc}
\hline Test result & H. pylori present & H. pylori absent & Total \\
\hline Positive & 30 & 3 & 33 \\
Negative & 11 & 120 & 131 \\
Total & 41 & 123 & 164 \\
\hline
\end{tabular}

This gives a sensitivity of $73.2 \%$ (CI: $57-86 \%$ ), specificity of $97.6 \%$ (CI: 93-99\%). The same samples tested on EIA showed a sensitivity of $86.8 \%$ (CI: $72-96 \%$ ), specificity of $100 \%$ (CI: $97-100 \%$ ). Conclusion: QuickVue One-Step is a useful easily performed and rapid screening test for the presence of $H$. pylori antibodies in children.

\section{B:20 VALIDATION OF THE ${ }^{13}$ C-UREA BREATH TEST TO ASSESS H. PYLORI ERADICATION IN CHILDREN}

G. Oderda, M. Harding ' ${ }^{\text {, J. Thomas }}{ }^{2}$, W. Coward ${ }^{1}$, F. Bazzoli ${ }^{3}$, M. Zagari ${ }^{3}$, P. Pozzato ${ }^{3}$, E. Chiorboli, P. Martelli, P. Lerro ${ }^{4}$, P. Caristo ${ }^{4}$, G. Bona. ${ }^{4}$ Novara, Torino, Italy; ${ }^{3}$ Bologna, Italy; ${ }^{1}$ Cambridge, UK; ${ }^{2}$ Newcastle, UK

The ${ }^{13} \mathrm{C}$-Urea Breath Test $\left({ }^{13} \mathrm{C}\right.$-UBT $)$ is a simple non invasive highly accurate test for the diagnosis of Helicobacter pylori $(H p)$ infection in adults and in children and can be used to assess $H p$ eradication after therapy in adults. We assessed its accuracy 1 or 2 and 6 weeks after stopping treatment in children. Patients \& Methods: We treated for Hp gastritis 59 children (M/F 31/28 median age 11 yr. range 6-14) with a 2-week therapy with Omeprazole + Clarithromicin + Amoxicillin (31 cases) or 1-week therapy with Omeprazole + Clarithromicin + Metronidazole (28 cases). Six weeks after treatment eradication was evaluated by Gastroscopy: antral and corpus biopsy specimens taken for microscopic evaluation of $\mathrm{Hp}$ (Giemsa stain) and urease test. The ${ }^{13} \mathrm{C}$-UBT was performed in each child the same day of endoscopy. In 32 of them ${ }^{13} \mathrm{C}$-UBT had been performed also 1 week and in 24 two weeks after stopping treatment. Dose of ${ }^{13} \mathrm{C}$-Urea was $50 \mathrm{mg}$, test meal: a $10 \%$ solution of Polycose (glucose polymer - Abbott) Breath samples were collected 30 minutes after and analyzed by an Automated Breath ${ }^{13} \mathrm{C}$ Analyzer (ABCA Europa Scientific). The "gold standard" to evaluate $H p$ infection was a concordant result of histology and urease-test. Results According to the "gold standard" in 42 children $\mathrm{Hp}$ infection was eradicated $(H p-v e)$, in 17 it was not $(H p+v e)$. One week after stopping treatment the ${ }^{13} \mathrm{C}$-UBT was positive in $9 \%$ of $\mathrm{Hp}$-ve children and negative in $56 \%$ of $\mathrm{Hp}$ +ve (specificity $91 \%$, sensitivity $44 \%$ ). Two weeks after stopping treatment the ${ }^{13} \mathrm{C}$-UBT was positive in $6 \%$ of $H p$-ve children and negative in $25 \%$ of $\mathrm{Hp}+\mathrm{ve}$ (specificity $94 \%$, sensitivity $75 \%$ ). Six weeks after stopping treatment the ${ }^{13} \mathrm{C}$-UBT was positive in $2.5 \%$ of $H p$-ve children and negative in $14.4 \%$ of $H p$ +ve (specificity $97.2 \%$ ), sensitivity $85.6 \%$ ). Conclusions The ${ }^{13} \mathrm{C}$-UBT is a simple, non invasive test that can be used to assess $H p$ eradication in children. Its specificity is very satisfactory even one week after treatment, but its sensitivity is very low. Two weeks after treatment its sensitivity increases, but its best accuracy is obtained six weeks after treatment.

\section{B:21 DETECTION \& QUANTIFICATION OF SERUM ANTIBODIES TO H. PYLORI SPECIFIC ANTIGENS IN CHILDHOOD HP GASTRITIS}

G. Oderda, P. Ravanini ${ }^{~}$, M.C. Malosso ${ }^{1}$, F. Altare, M. Forni, P. Lerro, P. Caristo, G. Fortina ' . Paediatric Gastroenterology, University of Torino \& Novara, Italy; ' Microbiology Lab. 'Maggiore' Hospital, Novara, Italy

Childhood H. pylori $(H p)$ gastritis can be associated with a variety of gastro-duodenal lesions due to different $H p$ strains and variable host response. Aim: To analyse serum immunoblot profile in children with $\mathrm{Hp+}$ gastritis and controls and relate type and intensity of antibody response to $H p$ antigens to severity of gastritis, before and after antibiotic treatment.

Patients \& Methods: Endoscopy was performed for dyspeptic symptoms in 35 children (M/F 20/15, median age 11 yr., range 4-14) Histology (Giemsa stain) and Rapid Urease (RUT) showed $\mathrm{Hp}+$ gastritis in 28 (active in 12), and $\mathrm{Hp}$ - normal antral mucosa in 7 (Controls). Sera were screened by immuno-probing of Western blots of $\mathrm{Hp}$ antigens (Helico Blot 2.0, Genelabs Diagnostic, Singapore) and a Scanblot to quantify band intensity. Serum Pepsinogen I (PGI) and Gastrin were measured by RIA. Serum reactivity to $H p$ antigens was reassessed $6 \mathrm{wk}$. after treatment in 23 children (13 had eradicated, 10 were still $\mathrm{Hp}+$ as assessed by histology and RUT).

Results: Control sera did not show any band, in $\mathrm{Hp}+$ children a mean of 6 bands were present. In all $\mathrm{Hp}+$ sera bands at $26 \mathrm{kDa}$ (Ure A) $60 \mathrm{kDa}$ (Ure B) and $57 \mathrm{kDa}$ (Heat Shock) were detected. A $19.5 \mathrm{kDa}$ band (adhesin) was detected in $82 \%$, a $116 \mathrm{kDa}$ band (CagA) in $53 \%$. The $116 \mathrm{kDa}$ band was more frequent in active gastritis $(\mathrm{p}<0.02)$ Mean serum PGI and Gastrin levels were higher in children with a $116 \mathrm{kDa}$ band in their serum $(78 \pm 24$ $\mathrm{pg} / \mathrm{ml}$ vs $55 \pm 13$ for PGI and $63 \pm 11 \mathrm{ng} / \mathrm{ml}$ vs. $32 \pm 9$ for Gastrin). The $116 \mathrm{kDa}$ band was present in pre-treatment sera in $90 \%$ of children where $H p$ eradication was not achieved, and in $38 \%$ of those who eradicated $(\mathrm{p}<$ 0.01 ). After $H p$ eradication the $19.5 \mathrm{kDa}$ band intensity was significantly decreased $(p<0.01)$ in eradicated children only.

Conclusion: Presence of serum antibodies against CagA, as assessed by Helico Blot 2.0, is related to a more severe gastric disease and a poorer response to antibiotic treatment. Band intensity of anti-adhesin antibodies significantly decreases $6 \mathrm{wk}$. after $\mathrm{Hp}$ eradication.

\section{B:22 TRIPLE THERAPY IN CHILDHOOD H. PYLORI GASTRITIS}

G. Oderda, P. Lerro, P. Caristo, M. Kuvidi, M. Forni, N. Ansaldi, P. Martelli, E. Chiorboli, G. Monga, G. Bona. Pediatric Gastroenterology, University of Turin \& Novara, Italy

In children with Helicobacter pylori $(\mathrm{Hp})$ gastritis dual therapy regimens with antibiotics with or without bismuth salts usually reach eradication rates ranging from 70 to $80 \%$ and triple therapy has seldom been tried.

We evaluated the usefulness of triple therapy in childhood $H p$ gastritis with Omeprazole plus Clarithromicin and Amoxicillin or Metronidazole.

Patients \& Methods: Hp gastritis was diagnosed by urease test and histology (Giemsa stain) in 79 children (M/F 44/35) median age 11 yrs (range 5-15). They were divided in two groups: a first one (group A: 45 children) was treated with a 2-week course of Omeprazole ( $1 \mathrm{mg} / \mathrm{kg}$ bid $)+$ Clarithomicin (15 mg/kg bid) + Amoxicillin ( $50 \mathrm{mg} / \mathrm{kg}$ bid) a second one (group B: 34 children) was treated with an 1-week course of Omeprazole $(0.5 \mathrm{mg} / \mathrm{kg}$ mane $)+$ Clarithomicin $(15 \mathrm{mg} / \mathrm{kg}$ bid $)+$ Metronidazole $(20$ $\mathrm{mg} / \mathrm{kg}$ bid). Six weeks after stopping treatment endoscopy was repeated and eradication proven by urease test and histology of both the antrum and the gastric corpus biopsies and ${ }^{13} \mathrm{C}$-Urea breath test (UBT).

Results: Six children refused repeated endoscopy and eradication was evaluated by UBT only. $\mathrm{Hp}$ was eradicated in 35 children of group A (77.7\%) in 23 of group B (67.6\%). Compliance was poor in 5 children of group A, and in 4 of group B.

Conclusions: Triple therapy for 1 or 2 weeks, with Omeprazole 1 or 2 times a day does not reach a better eradication rate than the average obtained with dual therapy for a poor patient compliance.

\section{B:23 PREVALENCE OF CagA-POSITIVE H. PYLORI STRAINS IN CHILDREN}

H. Rautelin ${ }^{1}$, J. Karhukorpi ${ }^{2}$, H. Lindahl ${ }^{1}$, K.L. Kolho ${ }^{1}$, R. Karttunen ${ }^{2}$. ${ }^{1}$ University of Helsinki, Helsinki, Finland; ${ }^{2}$ University of Oulu, Oulu, Finland

Persons harbouring $H$. pylori strains with cagA gene have been shown to have peptic ulcer disease more often than persons infected with cagAnegative strains. Only few studies are available on the prevalence of cagA-positive strains in children. Our purpose was to study how often cagA-positive $H$. pylori strains were isolated from Finnish children.

Methods. H. pylori was isolated from gastric biopsies of 13 children (6 males; age range, 2 to 16 years; median, 9 years; 5 of foreign origin) endoscopied for recurrent abdominal pain. The cagA-positive and cagA- 
negative strains were identified by PCR using cagA-specific primers $\left(5^{\prime}\right.$ GATAACAGGCAAGCTTTTGAGG-3', 5'-CTGCAAAAGATTGTTTGGCAGA-3'). For each bacterial specimen, bacterial genomic DNA was purified with QIAamp Tissue Kit (QIAGEN) and used as a template for PCR. The amplified fragment ( $349 \mathrm{bp}$ ) was detected by agarose gel electrophoresis.

Results. Nine of the 13 strains studied (70\%) were cagA-positive. All except one of the originally Finnish children had cagA-positive strains, whereas three of the five foreign children had cagA-negative strains.

Conclusion. The prevalence of cagA-positive $H$. pylori strains in children (70\%) is comparable to that reported in adult population.

\section{B:24 MOLECULAR TYPING OF H. PYLORI STRAINS ISOLATED FROM SIBLINGS AND UNRELATED CHILDREN}

H. Rautelin, M.L. Hänninen, H. Lindahl, K.L. Kolho, T.U. Kosunen. University of Helsinki, Helsinki, Finland

H. pylori strains isolated from different individuals have shown a high degree of heterogeneity by different molecular typing methods. Family members may also be infected with different strains. The purpose of the present study was to examine four $H$. pylori strains isolated from two siblings (females, 9 and 11 years of age) and two unrelated children (a female 10 years and a male 9 years of age). The methods used were RAPD (random amplified polymorpic DNA) and ribopattern analysis with HaeIII, $C l a I$ and $P v u I I$ restriction enzymes.

Results. Both RAPD and ribopattern analysis revealed that all strains were different.

Conclusion. H. pylori strains isolated from children are different as examined by molecular typing methods. Even sisters living in the same family may be infected with different strains in their childhood.

\section{B:25 SERUM AND SALIVARY ANTIBODIES TO H. PYLORI IN CHILDREN}

H. Rautelin ${ }^{1}$, M. Verkasalo ${ }^{2}$, T.U. Kosunen ${ }^{1} .{ }^{1}$ University of Helsinki, Finland; ${ }^{2}$ Aurora Hospital, Helsinki, Finland

The purpose of the present study was to determine serum and salivary antibodies to $H$. pylori in children with recurrent abdominal pain

Methods. Serum and unstimulated saliva samples were collected from 44 children ( 21 males; 3 to 17 years of age; mean 10 years) and stored at $-20^{\circ} \mathrm{C}$ prior to use. An in-house enzyme immunoassay with acid extract as antigen and with sensitivity of $97 \%$ (IgG and IgA) and specificity of $94 \%$ for serum in adult population was used to detect IgG and IgA antibodies in serum samples. For undiluted saliva samples, a modified Pyloriset EIA-G (Orion Diagnostica, Espoo, Finland) was used.

Results. A total of 21 of 44 children (48\%) showed elevated serum IgG antibody titers. Nine children showed both elevated IgG and IgA serum antibody titers. In comparison with the serum test, the salivary IgG test showed sensitivity of $78 \%$ and specificity of $95 \%$.

Conclusion. Salivary IgG antibodies could be used to screen for $H$. pylori infection in children, when serum samples might be difficult to be obtained.

\section{B:26 \\ NUTRITION AND H. PYLORI INFECTION IN COLOMBIAN} CHILDREN

K.J. Goodman ${ }^{1}$, P. Correa ${ }^{2}$, H. Tengańa ${ }^{3}$, J. DeLany ${ }^{2}$, T. Collazos.

${ }^{1}$ University of Texas School of Public Health, Houston, Texas, USA;

${ }^{2}$ Louisiana State University, New Orleans, Louisiana, USA $;^{3}$ Universidad del Valle, Cali, Colombia

We examined the effects of nutritional factors on the prevalence of $H$. pylori infection in 684 children, 2-9 years old, from an Andean village. $H$. pylori status was determined by the ${ }^{13} \mathrm{C}$-urea breath test. Consumption of milk, fruits, and vegetables was ascertained by questionnaire; intake of vitamin $\mathrm{C}$ and beta-carotene from these food items was derived from the Colombian Institute of Family Welfare food composition table. Height-forage and weight-for-height percentiles were derived from the international growth reference curve. Odds ratios (OR) and 95\% confidence intervals (CI) comparing low levels to high levels were estimated using logistic regression to adjust for relevant socioeconomic indicators:

\begin{tabular}{lrlc}
\hline & OR & CI & p-value \\
\hline $\begin{array}{l}\text { Fruits/vegetables (servings/day) } \\
\quad<2 \text { versus } \geq 3\end{array}$ & 19.6 & $4.1-93.4$ & $<0.001$ \\
$\begin{array}{l}\text { Vitamin C (mg/day) } \\
\quad<40 \text { versus } \geq 80\end{array}$ & 8.9 & $1.9-41.9$ & 0.005 \\
$\begin{array}{l}\text { Beta-carotene (IU/day) } \\
<300 \text { versus } \geq 900\end{array}$ & 3.1 & $1.2-7.9$ & 0.02 \\
\hline
\end{tabular}

Children who ate less than 2 fruit/vegetable servings/day had extremely high odds of infection, as did those whose vitamin $C$ intake was less than $40 \mathrm{mg} /$ day. Low beta-carotene intake reflected a more modest increase in infection. Children who drank less than two cups of milk daily, or had deficient height-for-age or weight-for-height were also more likely to be infected, although these associations were of marginal statistical significance.

Conclusion: Adequate intake of fruits and vegetables, particularly those rich in vitamin $\mathrm{C}$, may protect children against chronic H. pylori infection. 